\title{
A Critical Discourse Analysis of Radi's Dramas From behind the Windows and Hamlet with Season Salad Based on Van Leeuwen's Framework "Representing Social Actions"
}

\author{
Alireza Khormaee \\ Shiraz University, Iran \\ Rayeheh Sattarinezhad \\ Shiraz University, Iran
}

\section{Introduction}

In order to carry out research in the field of Discourse Analysis, it is essential to understand what discourse means. There are several approaches to Discourse Analysis and different research traditions have offered diverging definitions of the term based on implementations of different theoretical frameworks. Blommaert (2005: 2) defines discourse as a "meaningful symbolic behavior". This definition is not limited to linguistic communication; rather, it is related to semiotics and includes every kind of symbolic behavior. Accordingly, "discourse is what transforms our environment into a socially and culturally meaningful one" (Blommaert, 2005: 4).

On the other hand, Johnstone (2008: 2) regards discourse as "actual instances of communicative action in the medium of language". This means that discourse analysts must pay attention to what actually happens rather than what is merely abstract. Moreover, it is essential that this communicative action be performed through linguistic means. Consequently, a conversation, lecture, or written texts are all instances of discourse. In Johnstone's (2008: 3) view, some discourse analysts influenced by Foucault (1980 and 1972), think of discourse as "conventional ways of talking that both create and are created by conventional ways of thinking". This means that the important aspect of communication does not reside in the mere knowledge of language. If that is the case, a specific way of thinking that manifests itself in a specific conversation becomes conventionalized in the mind of the person who is exposed to said conversation. 
Generally speaking, through critical analysis, it is possible to decipher the underlying ideologies that inform specific discourses. Therefore, critical discourse analysis shows that language is not just a tool for communication. In fact, careful use of rhetorical devices may result in the crystallization of specific ways of thinking or, more commonly, the acquisition of personal gains.

Fairclough (2006: 12) says that the adjective 'critical' is added to Discourse Analysis because, unlike previous approaches, Critical Discourse Analysis (CDA) explains "not only the discursive practices, but also showing how discourse is shaped by relations of power and ideologies". Therefore, CDA reveals the building effect of discourse on social identities, social relations, beliefs and systems of thought. In other words, Critical discourse analysis implies "the opaque relationships of causality ... linkages which are not clear to those involved". (Fairclough, 1995: 132-33).

Caldas-Coultard and Coultard (2003: xi) think of discourse as a "major instrument of power". "Critical Discourse Analysis is essentially political in intent with its practitioners acting upon the world in order to transform it and thereby help create a world where people are not discriminated against because of sex, color, creed, age or social class". Van Dijk (1996: 84) clarifies what power refers to in discourse studies: "Power is a property of relations between social groups, institutions or organizations. Hence, only social power, and not individual power, is considered here."

In Fairclough and Wodak's words (1997) all main trends of discourse analysis share some characteristics (Fairclough and Wodak, 1997: 353):

1. CDA addresses social problems

2. Power relations are discursive

3. Discourse constitutes society and culture

4. Discourse does ideological work

5. Discourse is historical

6. The link between text and society is mediated

7. Discourse analysis is interpretative and explanatory

8. Discourse is a form of social action.

Critical Discourse analysis is usually based on specific frameworks. Many researchers have studied different discourses using a CDA approach. Post (2008) applies van Leeuwen's Social Actor Network (2008) into analyzing six campaign speeches of Barack Obama and John McCain from the 2008 US election and notes that the linguistic choices these two candidates make, are indeed purposeful and based on their opposing ideologies. Rahimi, Amal Saleh, and Deghat (2010), Benoit and Henson (2009), Rashidi and Souzandehfar (2010) have all applied a critical approach based on a CDA framework in the analysis of political discourses. 
Rashidi, Khormaei, and Zarei (2014) have studied four short stories by Bozorg Alavi. Applying Hodge and Kress's (1996) syntagmatic models. hey contend that different statuses of men and women in these short stories are reflected in their languages. Hobson (2003)and Smith (2002) are among the researchers who have tried to critically analyze literary pieces of work with regards to either gender, age, or social class.

As can be seen, by analyzing real examples of the language, it is possible to show that authors and speakers use specific linguistic expressions to promote their own agendas. One of the other frameworks devised in the field of CDA is van Leeuwen's (2008) 'Representing Social Actions'. Our primary analyses have shown that this framework, which is usually applied to the analysis of political discourses, also proven effective in the analysis of literary works, namely Akbar Radi's dramas. Radi usually contrasts the discourse of the inactive and secluded intellectuals and the active and generative discourse of the bourgeois. The endings of his dramas portrait the defeat of the dominated intellectuals and the victory of the dominant bourgeois. Therefore, our intention is to apply van Leeuwen's framework to the analysis of the differences between the above-mentioned social groups in order to demonstrate how linguistic choices (representing actions) shape two distinct discourses. No previous research has been done on dominant and dominated characters in a drama based on the aforementioned framework and the present study is the first to investigate how power relations are reflected in the social actions of the dominated intellectuals and dominant bourgeois of Iran.

\section{A. Importance of the Research}

Throughout history, authors have always tried to use literary devices to convey their ideas in attractive ways. It is not easy to make sense of the intricacies that authors implement in their literary works. Dramas in particular are more difficult to decipher because of the lack of comments provided by the narrator and the absence of explicit reasons as to why a specific character behaves in a certain way. It falls upon the audience to interpret the events. In order to reveal the underlying motivations of an author, it is therefore necessary to analyze such discourses from a linguistic point of view.

\section{B. Objective of the Study and Research Questions}

Applying van Leeuwen's framework, the present study sheds light on the different linguistics choices made by Akbar Radi in his dramas From behind the Windows and Hamlet with Season Salad. In so doing, we offer an explanation as to how the different ideologies of the intellectuals and the bourgeois are represented in their linguistic choices. In order to do so, we need to answer the following research questions: 
Q1) Can we account for the author's linguistic choices for each of the two opposing groups based on van Leeuwen's framework?

Q2) How do the characters' social actions help shape two opposing discourses?

\section{Methodology}

\section{A. Corpus}

Two dramas by Akbar Radi, From behind the Windows and Hamlet with Season Salad, were chosen and four characters belonging to two opposing social classes (two females and two males) were selected.

\section{B. Procedure}

Each of the four characters' social (re)actions have been analyzed, and categorized based on van Leeuwen's (2008) framework 'Representing Social Actions'.

\section{Theoretical Framework}

As already mentioned, the present study applies van Leeuwen's (2008) framework Representing Social Actions in Discourse in the analysis of Radi's dramas. In this model, social actions are divided into five binaries:

1. Action and Reaction

2. Activation and Deactivation

3. Agentialization and Deagentialization

4. Abstraction and Concretization

5. Single determination and Overdetermination

According to him, each type of action reveals the peculiarities of an author's system of thought. " ...the discursive distribution of purposefulness has everything to do with the distribution of power in concrete social practices .... and in society generally..." (vanLeeuwen, 2008: 135). Thus, as van Leeuwen maintains, through wise discursive choices, authors shape their audience's ways of thinking in accordance to specific underlying worldviews. In other words, we can say that authors convey the values they uphold by attributing qualitatively different social actions to their fictional characters. Furthermore, social actions that are in line with an author's ideology are quantitatively overrepresented and qualitatively identifiable based on specific linguistic choices.

\section{Results and Discussion}

In an era of sociopolitical repression in Iran, Radi chose the drama as a safe way of depicting the situation without being explicit. His dramas often feature the two opposing discourses of the intellectuals and the bourgeois. He is primarily concerned about the isolation of Iranian intellectuals. The two dramas that we have 
chosen reflect the sociopolitical issues of the time, the isolation of the intellectuals, the increasing power of the bourgeoisie, and its domination over the intellectuals. Given the fact that the adopted framework allows us to scrutinize different texts and reveal the author's techniques, we will analyze the ways in which various linguistic choices reflect different discourses.

\section{A. From behind the Windows}

In From behind the Windows, Bamdad and Maryam are representatives of the Iranian subordinate intellectuals in the 60s. On the other hand, Mr. and Mrs. Derakhshan represent the dominant bourgeoisie. We have chosen two women (Maryam and Mrs. Derakhshan) from each social group in order to avoid gender biases. Moreover, these two characters do not differ much in the number of their social actions.

\section{Cognitive vs. Affective and Perceptive Reactions}

Actions are the physical acts of a social actor, whereas reactions comprise behaviors, feelings, and thoughts as responses to other people's actions or natural events. Van Leeuwen identifies four types of reactions, namely unspecified, cognitive, affective and perceptive. Unspecified reactions are mere reactions with no affective content (e.g. reply, answer, etc.). Cognitive reactions (or in van Leeuwen's words "Cognitive Mental Processes") refer to ideologies (e.g. think, believe, understand, etc.). According to him, the more powerful the social actors, and the higher their social status, the more cognitive reactions they show. Affective reactions, on the other hand, reflect the actors' feelings of happiness, horror, despair, etc. as well as their needs, wishes, and hopes. Lastly, perceptive reactions refer to the perception of actions by a social actor (e.g. see, hear, smell, etc.).

In many scenes of this drama, the way in which Mrs. Derakhshan expresses her beliefs, thoughts, and ideas implicitly suggests that she is qualified to evaluate each and every action or event (Radi, 2009: 22, 51):

-Mrs. Derakhshan: I know [it is all because] I've had a lot to deal with since

Kaveh [was born].

-Mrs. Derakhshan: In my opinion, moderation is the key to salvation.

-Mrs. Derakhshan: I believe one should not smoke so heavily that the seat smells like cigarettes.

On the other hand, Maryam rarely states her ideas about anything, regardless of her being asked about it, she "does not know" (Radi, 2009: 16, 39).

-Bamdad: Really?! What is it that I do [which hurts you]?

-Maryam: I don't know...you are sometimes sneaky.

-Bamdad: Maryam... What is it? Is something wrong?

-Maryam: No...Nothing. I don't know what's wrong with me...

-Bamdad: How about we hire someone to do the house chores? 
-Maryam: I don't know... I don't know...

However, there are many instances of Maryam expressing her feelings - usually unfulfilled desires and wishes upon which she never acts to gain what she yearns for (Radi, 2009: 9):

-Maryam: I wish we had a piece of land to ourselves...we could grow flowers and make a nice home...

This desire is never realized. In fact, Maryam and her husband will continue living in the same old, dark and gloomy apartment until the very end. Maryam is often brooding over her lost hopes. (Radi, 2009: 59):

-Maryam: What a beautiful flower it was...!

On the other hand, Mrs. Derakhshan is usually reacting cognitively rather than affectively. Interestingly, even her affective reactions are rational and based on cognitive processes (Radi, 2009: 43):

-Mrs. Derakhshan: No news from Kaveh... and I'm so afraid of his driving...he drives recklessly.

Mrs. Derakhshan's fear is due to the fact that her son is a dangerous driver. In other words, her fear is not a mere irrational feeling, but a feeling based on fact, i.e. a rational conclusion. Although there is not much difference in the number of perceptive reactions Maryam and Mrs. Derakhshan show, the latter usually shows negative perceptive reactions only when she is judging Maryam or her husband (Radi, 2009: 24, 67):

-Mrs. Derakhshan: I smell too much smoke here....

-Mrs. Derakhshan: We did ring the bell...but...There's too much noise here...

In these examples, Mrs. Derakhshan is reacting to Maryam's husband. She does not approve of his smoking and listening to very loud music. Van Leeuwen states that the higher the social actors' status, the more cognitive their reactions will be. On the other hand, perceptive and affective reactions are mostly attributed to social actors of a lower status. As can be seen in Table I, cognitive reactions of Mrs. Derakhshan (about 55\%) amount to more than her affective and perceptive reactions combined (about 45\%). In other words, the fact that she usually reacts rationally to the events and other people's actions provides her with a higher status in the reader's mind.

Table 1. Reactions of the dominant character: Mrs. Derakhshan

\begin{tabular}{|l|l|l|}
\hline \multicolumn{1}{|c|}{ Types of Reactions } & \multicolumn{1}{c|}{ Number } & \multicolumn{1}{c|}{ Percentage } \\
\hline Cognitive & 53 & 55.21 \\
\hline Affective & 37 & 38.54 \\
\hline Perceptive & 6 & 6.25 \\
\hline Total Reactions & 96 & 100 \\
\hline
\end{tabular}


Maryam, on the other hand, shows affective/perceptive reactions about $88 \%$ of the time and her cognitive reactions constitute only $12 \%$ of her total reactions. Affective and perceptive reactions show Maryam's passivity and underline her status as a dominated character. Table 2 summarizes Maryam's reactions.

Table 2. Reactions of the dominated character: Maryam

\begin{tabular}{|l|l|l|}
\hline \multicolumn{1}{|c|}{ Types of Reactions } & \multicolumn{1}{c|}{ Number } & \multicolumn{1}{c|}{ Percentage } \\
\hline Cognitive & 28 & 12.17 \\
\hline Affective & 184 & 80 \\
\hline Perceptive & 18 & 7.83 \\
\hline Total Reactions & 230 & 100 \\
\hline
\end{tabular}

\section{Material vs. Semiotic Actions}

One of the other binaries that shape and reflect the dominant and dominated discourses is material vs. semiotic actions. Material actions refer to physical acts and do not point to any purpose beyond the surface act itself (e.g. eat, come, go, etc.) (Radi, 2009: 80, 44):

-Maryam: I will attach your hideous mustache to an electric cable.

-Mrs. Derakhshan: I brought you some winter sweets.

On the contrary, semiotic actions refer to social actions whose purpose is not limited to the mere physical dimension. In other words, the use of metaphors and allusions have the potential of representing semiotic actions (Radi, 2009: 21, 78): -Mrs. Derakhshan: I told him to stop the car so that we could check on you. -Maryam: In order to find an excuse for stopping by, I plan ahead thousands of times.

There is a negative correlation between the number of material actions and the social status of the actors. Therefore, we expect Mrs. Derakhshan to have more semiotic actions than material ones. As can be seen in Table III, Mrs. Derakhshan's semiotic actions constitute over $72 \%$ of her social actions, whereas her material actions represent only $27 \%$.

Table 3. Material vs. semiotic actions of the dominant character: Mrs. Derakhshan

\begin{tabular}{|l|l|l|}
\hline Types ofActions & Number & Percentage \\
\hline Material & 27 & 27.27 \\
\hline Semiotic & 72 & 72.73 \\
\hline TotalActions & 99 & 100 \\
\hline
\end{tabular}


Furthermore, Maryam's material (about 80\%) and semiotic actions (about 20\%) follow the same trend. In fact, her actions are often purely physical and do not involve any purposes other than the action itself (see Table 4).

Table 4. Material vs. semiotic actions of the dominated character: Maryam

\begin{tabular}{|l|l|l|}
\hline Types of Actions & Number & Percentage \\
\hline Material & 117 & 79.6 \\
\hline Semiotic & 30 & 20.4 \\
\hline TotalActions & 147 & 100 \\
\hline
\end{tabular}

Comparing the two tables above confirms van Leeuwen's claim that semiotic actions are often attributed to the dominant characters of a higher status.

\section{Transactive vs. Non-Transactive Actions}

Material and semiotic actions can be represented in two different ways, namely transactive and non-transactive. Transactive actions include an actor and a patient. If an actor's social action affects another entity, such an action is a transactive one (Radi, 2009: 30, 13):

-Mrs. Derakhshan: I was parking the car...

-Maryam: I water all the flowers.

On the other hand, non-transactive actions include and affect only a single actor. Examples of non-transactive actions can be found in daily activities (Radi, 2009: 41,7):

-Maryam: I came here a little late.

-Mrs. Derakhshan: Whenever I come here...

Transactive actions require a certain amount of power that not every actor possesses. Thus, we would expect Mrs. Derakhshan to have more transactive actions rather than non-transactive ones. Once again, the data (Table 5) is in line with the framework's predictions.

Table 5. Transactive vs. non-transactive actions of the dominant character: Mrs. Derakhshan

\begin{tabular}{|l|l|l|}
\hline Types ofActions & Number & Percentage \\
\hline Transactive & 67 & 67.68 \\
\hline Non-Transactive & 32 & 32.32 \\
\hline TotalActions & 99 & 100 \\
\hline
\end{tabular}


As already mentioned, van Leeuwen attributes non-transactive actions to the lower-status actors. Table 6 below shows Maryam's transactive vs. non-transactive actions.

Table 6. Transactive vs. non-transactive actions of the dominated character: Maryam

\begin{tabular}{|l|l|l|}
\hline Types of Actions & Number & Percentage \\
\hline Transactive & 55 & 40.14 \\
\hline Non-Transactive & 82 & 59.86 \\
\hline TotalActions & 137 & 100 \\
\hline
\end{tabular}

As can be seen, the difference between these two types of actions helps the author create a passive, dominated character (Maryam) and an active, dominant one (Mrs. Derakhshan).

\section{Interactive vs. Instrumental Actions}

Transactive actions are divided into two subtypes, namely interactive and instrumental actions. In interactive actions, both the actor and the patient are human and the action is specific to the human being (Radi, 2009: 21, 44):

-Mrs. Derakhshan: I don't want to give you a headache...

-Maryam: I congratulated you...

Instrumental actions, on the other hand, usually include a non-human patient (Radi, 2009: 77, 75):

-Maryam: I hung the clothes to dry.

-Mrs. Derakhshan: The day I cut that ribbon...

As van Leeuwen explains, the more an actor interacts with other people and affects them, the more powerful such actor is. When an actor can rarely affect others and their actions only extend to things or animals rather than human beings, such actor does not have a high status. Hence, we would expect Mrs. Derakhshan and Maryam to show more interactive and instrumental actions respectively. Table 7 shows Mrs. Derakhshan's interactive and instrumental actions.

Table 7. Interactive vs. instrumental actions of the dominant character: Mrs. Derakhshan

\begin{tabular}{|l|l|l|}
\hline Types of Actions & Number & Percentage \\
\hline Interactive & 43 & 64.17 \\
\hline Instrumental & 24 & 35.83 \\
\hline Total Actions & 67 & 100 \\
\hline
\end{tabular}


We now take a look at Maryam's interactive and instrumental actions as presented in Table 8 .

Table 8. Interactive vs. instrumental actions of the dominated character: Maryam

\begin{tabular}{|l|l|l|}
\hline Types of Actions & Number & Percentage \\
\hline Interactive & 7 & 12.73 \\
\hline Instrumental & 48 & 87.27 \\
\hline Total Actions & 55 & 100 \\
\hline
\end{tabular}

The two tables above clearly show the contrast between Mrs. Derakhshan and Maryam's social status. Over $87 \%$ of Maryam's actions do not include a human patient, whereas over $64 \%$ of Mrs. Derakhshan's actions are exclusively humanoriented.

\section{B. Hamlet with Season Salad}

In order to avoid gender biases in Hamlet with Season Salad, two male characters, Damagh and Alijenab, are selected as representatives of the subordinate intellectuals and the dominant bourgeois, respectively. In what follows, we will explain how different types of social actions help create two distinct dominant and dominated discourses in this drama.

\section{Cognitive vs. Affective and Perceptive Reactions}

As already stated, cognitive reactions show mental processes and refer to a person's thoughts. Below are two examples. (Radi, 2008: 324, 311):

-Alijenab: Yes! Sure! I believe in your taste...

-Damagh: I think; therefore, I am...

Affective reactions include different types of feelings such as fear, joy, and pleasure as well as needs, desires, demands, hopes, and wishes. Alijenab's affective feelings are essentially different from Damagh's. Alijenab demands and orders something he wants done (Radi, 2008: 324):

-Alijenab: I want to know who the hell he is, based on the report!

In this example, he wants Mahsima (his niece) to read him a report about Damagh and instead of asking, he just states his demand. Damagh's affective reactions on the other hand, simply show how he feels about a situation (Radi, 2008: 301):

-Damagh: I don't wanna go to the park on a sunny day...

Perceptive reactions, which show passivity and have no purpose, can be found in both characters' speech as well. Below are two examples of perceptive reactions in this drama (Radi, 2008: 335, 404): 
-Alijenab: And this horrible smell! ...

-Damagh: There was...there was this weird smell.

Table 9 summarizes Alijenab's reactions.

Table 9. Reactions of the dominant character: Alijenab

\begin{tabular}{|l|l|l|}
\hline $\begin{array}{l}\text { Types of } \\
\text { Reactions }\end{array}$ & Number & Percentage \\
\hline Cognitive & 46 & 70.77 \\
\hline Affective & 15 & 23.07 \\
\hline Perceptive & 4 & 6.16 \\
\hline TotalReactions & 65 & 100 \\
\hline
\end{tabular}

It can be seen that this dominant character's cognitive reactions (about 71\%) are much more numerous than his affective and perceptive reactions combined (about $29 \%$ ). The data provided in this table confirms van Leeuwen's theory: cognitive reactions belong to the more powerful.

We now turn to the dominated character's reactions. Based on the framework, we expect him to show fewer cognitive reactions and more affective and perceptive ones. Damagh's reactions are summarized in Table 10.

Table 10. Reactions of the dominated character: Damagh

\begin{tabular}{|l|l|l|}
\hline $\begin{array}{l}\text { Types of } \\
\text { Reactions }\end{array}$ & Number & Percentage \\
\hline Cognitive & 12 & 12.5 \\
\hline Affective & 38 & 79.17 \\
\hline Perceptive & 4 & 8.33 \\
\hline Total Reactions & 54 & 100 \\
\hline
\end{tabular}

We can see that Damagh's affective or perceptive reactions amount to $87.5 \%$ of his social actions, underscoring his lower status and lack of power. Only $12.5 \%$ of his reactions are cognitive and require cognitive mental processes.

\section{Material vs. Semiotic Actions}

As mentioned before, material actions refer to physical acts while semiotic actions show an intention beyond the mere material action. Below are examples of material actions (Radi, 2008: 364, 293):

-Alijenab: I smoked hookah by the Sea of Marmara

-Damagh: I will do the buttons. 
However, there are also many instances of semiotic actions in this drama (Radi, 2008: 397, 300):

-Alijenab: I honored this dishonored [man] with a ring.

-Damagh: I nagged a lot...

One of the significant characteristics of this drama, is the use of imperative actions. Based on the fact that imperatives do not involve doing/acting and that they imply the social actor's power, such actions fall within the semiotic rather than the material category. Below are instances of imperatives in Hamlet with Season Salad (Radi, 2008: 335, 322):

-Alijenab: And this horrible smell! Pfff! Step away...Dunno where it comes from. Is it his feet or his head?

-Damagh: Mussy... hold my back...

These two examples shows how Alijenab exerts his power over others, whereas Damagh has no power to order anyone to do anything. As a result, Damagh rather asks others for help and is often the recipient of a dominant character's orders. He rarely has enough confidence and courage to give orders to other people and when he

does, it is rather a request in the form of an imperative.

According to van Leeuwen, Semiotic actions are usually attributed to more powerful characters, whereas material ones are found more frequently in the speech of the less powerful actors. Table 11 shows Alijenab's material and semiotic actions.

Table11. Material vs. semiotic actions of the dominant character: Alijenab

\begin{tabular}{|l|l|l|}
\hline $\begin{array}{l}\text { Types of } \\
\text { Actions }\end{array}$ & Number & Percentage \\
\hline Material & 21 & 14 \\
\hline Semiotic & 129 & 86 \\
\hline $\begin{array}{l}\text { Total } \\
\text { Actions }\end{array}$ & 150 & 100 \\
\hline
\end{tabular}

As can be seen, semiotic actions constitute $86 \%$ of Alijenab's actions. In other words, most of Alijenab's actions are meaningful and extend beyond a mere physical act. However, as predicted by the framework, we expect Damagh to perform more material actions than semiotic ones. Table 12 summarizes this dominated character's material and semiotic actions.

Table 12. Material vs. semiotic actions of the dominated character: Damagh

\begin{tabular}{|l|l|l|}
\hline Types of Actions & Number & Percentage \\
\hline Material & 71 & 55.47 \\
\hline Semiotic & 57 & 44.53 \\
\hline Total Actions & 128 & 100 \\
\hline
\end{tabular}




\section{Transactive vs. Non-Transactive Actions}

As mentioned in the previous section, material and semiotic actions can be represented in two different ways. Transactive actions include an actor and a patient. Below are two examples (Radi, 2008: 371, 385):

-Alijenab: I made muqarnas and vaults in the ceiling.

-Damagh: During the extra hours, I would clean the peas and the beans.

In the above examples, the actions include a patient and extend to entities other than the actor himself. On the other hand, non-transactive actions include and affect only one actor/patient. See the two examples below (Radi, 2008: 365, 380): -Alijenab: Yes, yes... with the permission of the master, I will speak a little... -Damagh: I was sitting in the next room.

As we already mentioned, transactive actions require a certain amount of power; which is why we expect Alijenab to have more transactive actions than nontransactive ones (Table 13).

Table 13. Transactive vs. non-transactive actions of the dominant character: Alijenab

\begin{tabular}{|l|l|l|}
\hline Types of Actions & Number & Percentage \\
\hline Transactive & 133 & 88.67 \\
\hline Non-Transactive & 17 & 11.33 \\
\hline TotalActions & 150 & 100 \\
\hline
\end{tabular}

Van Leeuwen attributes transactive actions to the higher social class and nontransactive ones to the subordinate characters of a lower class. Thus we expect Damagh to show fewer transactive actions (see Table 14).

Table 14. Ttransactive vs. non-transactive actions of the dominated character: Damagh

\begin{tabular}{|l|l|l|}
\hline Types ofActions & Number & Percentage \\
\hline Transactive & 54 & 42.18 \\
\hline Non-Transactive & 74 & 57.82 \\
\hline TotalActions & 128 & 100 \\
\hline
\end{tabular}

\section{Interactive vs. Instrumental Actions}

The last dichotomy differentiates interactive actions from instrumental ones based on their patients. Interactive actions include two human participants and an action which is exclusively human. Below are two examples (Radi, 2008: 395, 407):

-Alijenab: We should consider each other's needs.

-Damagh: First, I bow to all of you. 
Instrumental actions often include a non-human patient. See the two following examples (Radi, 2008: 336, 384):

-Alijenab: I will tie the reins there...

-Damagh: I used to remove the dust from stagnant documents.

Considering the fact that interactive actions show the actor's power, we expect Alijenab to have more interactive actions (Table 15).

Table 15. Interactive vs. instrumental actions of the dominant character: Alijenab

\begin{tabular}{|l|l|l|}
\hline Types ofActions & Number & Percentage \\
\hline Interactive & 104 & 80.62 \\
\hline Instrumental & 25 & 19.38 \\
\hline TotalActions & 129 & 100 \\
\hline
\end{tabular}

While over $80 \%$ of Alijenab's actions are interactive and show his power to affect people rather than objects or animals, Damagh's instrumental actions outweigh his interactive actions (Table 16). In other words, he can only affect objects (documents) or animals (mice) and rarely does he have any power over other people.

Table 16. Interactive vs. Instrumental actions of the dominated character : Damagh

\begin{tabular}{|l|l|l|}
\hline Types ofActions & Number & Percentage \\
\hline Interactive & 11 & 20.37 \\
\hline Instrumental & 43 & 79.63 \\
\hline TotalActions & 54 & 100 \\
\hline
\end{tabular}

\section{Conclusion}

Having analyzed the social actions of the four characters, we may now seek answers to our research questions. Table 17 summarizes the full data set gathered from the two dramas so that we may compare both of the dominant characters with the two dominated ones at a glance. 
Table 17. Summary of the (re)actions analyzed in the two dramas

\begin{tabular}{|l|l|l|l|l|}
\hline Titles of the Dramas & \multicolumn{3}{|l|}{$\begin{array}{l}\text { From behind the } \\
\text { Windows }\end{array}$} & \multicolumn{2}{|l|}{$\begin{array}{l}\text { Hamlet with Season } \\
\text { Salad }\end{array}$} \\
\hline Character Types & Dominant & Dominated & Dominant & Dominated \\
\hline $\begin{array}{l}\text { Types of Characters' } \\
\text { (re)actions Names }\end{array}$ & $\begin{array}{l}\text { Mrs. } \\
\text { Derakhshan }\end{array}$ & Maryam & Alijenab & Damagh \\
\hline Cognitive Reactions & 55.21 & 12.17 & 70.77 & 12.5 \\
\hline $\begin{array}{l}\text { Affective and Perceptive } \\
\text { Reactions }\end{array}$ & 44.79 & 87.83 & 29.23 & 87.5 \\
\hline Material Actions & 27.27 & 79.6 & 14 & 55.47 \\
\hline Semiotic Actions & 72.73 & 20.4 & 86 & 44.53 \\
\hline Transactive Actions & 67.68 & 37.41 & 88.67 & 42.18 \\
\hline Non-transactive Actions & 32.32 & 55.79 & 11.33 & 57.82 \\
\hline Interactive Actions & 64.17 & 12.83 & 78.2 & 20.37 \\
\hline Instrumental Actions & 35.83 & 87.27 & 18.8 & 79.63 \\
\hline
\end{tabular}

We now refer back to the research questions:

Q1) Can we account for the author's linguistic choices for each of the two opposing groups based on van Leeuwen's framework?

Q2) How do the character's social actions help shape two opposing discourses?

In order to answer these questions, we need to look back at the above table. As we can see, these four characters vary in their use of social (re)actions. Mrs. Derakhshan and Alijenab have a higher number of cognitive reactions and perform more semiotic, transactive, and interactive actions. While Maryam and Damagh have a higher number of affective and perceptive reactions and perform more material, non-transactive, and instrumental actions. Moreover, the first group of social (re)actions suggests higher status and domination, whereas the second group is often attributed to the subordinate, dominated, and less powerful social actors. Furthermore, Mrs. Derakhshan and Alijenab are from the bourgeoisie while Maryam and Damagh belong to the isolated subordinate intellectual category. Therefore, we conclude that the two opposing discourses of the dominant and the dominated are formed through the distinction between four types of (re)actions:

1) Cognitive vs. Affective and Perceptive Reactions

2) Material vs. Semiotic Actions

3) Transactive vs. Non-Transactive Actions

4) Interactive vs. Instrumental Actions

The evidence presented in our research demonstrates that the framework 'Representing Social Actions in Discourse' proves effective in the analysis of these two literary works. Moreover, the social (re)actions clearly highlight the power relations between actors and social classes. In other words, this framework can effectively account for the author's linguistic choices which are realized through the representatives of different discourses. 


\section{References and notes:}

Blommaert, J. (2005). Discourse: A critical introduction. New York: Cambridge University Press.

Benoit, W. and Henson, J. (2009). President Bush's image repair discourse on Hurricane Katrina. Public Relations Review, 35(1): 40- 46.

Caldas-Coulthard, C. R., \&Coultard, M. (2003). Texts and practices: Readings in critical discourse analysis. New York: Routledge.

Fairclough, N. L. (1995). Critical discourse analysis: The critical study of language. New York: Longman Group Ltd.

Fairclough, N. L. (2006). Discourse and social change. Cambridge: Polity Press.

Fairclough, N. L. \&Wodak, R. (1997). Critical discourse analysis. In T. A. Van Dijk (Ed.), Discourse studies: A multidisciplinary introduction (Vol. 2, pp. 352-71). London: Sage.

Foucault, M. (1972). The archaeology of knowledge and the discourse on language (tr. S. S. Smith). New York: Harper.

Foucault, M. (1980). Power/knowledge: selected interviews and other writings, 1972-1977 (ed. C. Gordon). New York: Pantheon

Hobson, H. (2003). A discussion of the representation of masculinity and femininity in Baden-Powell's 1919 handbooks for scouts and guides using the frameworks of Theo van Leeuwen, within the tradition of critical discourse analysis. Unpublished master's thesis. Lancaster University: United Kingdom. Retrieved May 6, 2015, from http://www.ling.lancs.ac.uk/staff/mark/web201/samples.htm.

Hodge, R and Kress, G. (1996). Language as ideology. London: Redwood Books.

Johnstone, B. (2008). Discourse analysis. Malden, Massachusetts: Blackwell Publishing.

Post, M. D. (2008). Representations of meaning within textual persona: An analysis of 2008 US presidential campaign speeches. Unpublished master's thesis, University of Birmingham, UK.

Rahimi, M., Amal Saleh, E., \&Deghat, S. (2010). The CDA of 2008 presidential campaign speeches of democratic candidates with respect to their gender \& race. Iranian Journal of Applied Linguistics, 13(2), 75-99.

Rashidi, N., Khormaei, A. \&Zarei, M. (2014). The critical discourse analysis of the representation of women and men in Bozorg Alavi's short stories. Advances in Language and Literary Studies, 5(3), 126-133.

Rashidi, N. and Souzandehfar, M. (2010). A critical discourse analysis of the debates between republicans and democrats over the continuation of war in Iraq. The Journal of Linguistic and Intercultural Education - JoLIE, 3,55-82.

Radi, A. (2009). From behind the windows (1st ed). Tehran, Iran: Qatre Publications

Radi, A. (2008). On the blue scene: Collection of writings (Vol. 2). Tehran, Iran: Qatre Publications

Smith, R. (2002). Young children's interpretations of gender from visual text and narrative. Linguistics and Education, 7(4): 303-325.

Van Dijk. T. (1996). Discourse, power, and access. In C. R. Caldas-Coulthard, \& M. Coulthard (Eds.). Texts and practices: Readings in critical discourse analysis (pp. 84-104). New York: Routledge.

Van Leeuwen, T. (2008). Discourse and practice. Oxford: Oxford University Press. 


\title{
Summary
}

\section{A Critical Discourse Analysis of Radi's Dramas 'From behind the Windows' and 'Hamlet with Season Salad' Based on Van Leeuwen's Framework "Representing Social Actions"}

\author{
Alireza Khormaee \\ Shiraz University, Iran \\ Rayeheh Sattarinezhad \\ Shiraz University, Iran
}

Different representations of social actions create distinct types of discourses. Applying van Leeuwen's 'Social Actions' framework (2008), the present study critically analyzes the power relations between the main characters of Radi's dramas From behind the Windows and Hamlet with Season Salad. The objective of our study is to account for the differences between the discourse of the dominant and the discourse of the dominated. In order to elucidate such differences we count and analyze the characters' social (re)actions and, in turn, identify four types of contrasts: cognitive vs. affective and perceptive reactions; material vs. semiotic actions; transactive vs. non-transactive actions; interactive vs. instrumental actions. Two opposing discourses emerge from these contrasts. On the one hand, the dominant characters mostly react cognitively and their actions are often semiotic, transactive, and interactive. On the other hand, the dominated characters' reactions are often affective and perceptive, while most of their actions are material, non-transactive, and instrumental. As the results show, the author's linguistic choices underscore the power relations between the dominant and the dominated characters. Building upon the fact that our analysis sheds light on the underlying ideologies and intentions of the author, we tentatively conclude that despite its being predominantly employed in the analysis of political discourses, van Leeuwen's framework also proves effective in the critical analysis of literary works.

Keywords: Social action, critical discourse analysis, representation, dominant, dominated, power relations, ideology 